\title{
Six Critical Ingredients in Creating an Effective Workplace
}

\author{
Jenet I. Jacob \\ Brigham Young University - Provo \\ James T. Bond \\ Families and Work Institute \\ Ellen Galinsky \\ Families and Work Institute \\ E. Jeffrey Hill \\ Brigham Young University - Provo, jeff_hill@byu.edu
}

Follow this and additional works at: https://scholarsarchive.byu.edu/facpub

Part of the Other Social and Behavioral Sciences Commons

\section{Original Publication Citation}

Jacob, J. I., Bond, J. T., Galinsky, E., \& Hill, E. J. (2008). Six critical ingredients in creating an effective workplace. The Psychologist-Manager Journal, 11(2), 141-161.

\section{BYU ScholarsArchive Citation}

Jacob, Jenet I.; Bond, James T.; Galinsky, Ellen; and Hill, E. Jeffrey, "Six Critical Ingredients in Creating an Effective Workplace" (2008). Faculty Publications. 4176.

https://scholarsarchive.byu.edu/facpub/4176 


\title{
Six Critical Ingredients in Creating an Effective Workplace
}

\author{
Jenet I. Jacob \\ Brigham Young University \\ James T. Bond and Ellen Galinsky \\ Families and Work Institute \\ E. Jeffrey Hill \\ Brigham Young University
}

\begin{abstract}
Using a nationally representative sample of data collected from waged and salaried employees in the United States $(n=2810)$ by the 2002 National Study of the Changing Workforce (NSCW), we evaluate workplace flexibility as another critical ingredient in creating an effective workplace. The study examined the bivariate relationships between six factors of workplace effectiveness and three job outcomes (job engagement, job satisfaction, employee retention) and one employee outcome (mental health). It also examined the relationship between a composite measure of overall workplace effectiveness and the four outcomes. Results indicated that all six aspects of workplace effectiveness and the composite measure of overall workplace effectiveness were strongly and positively related to job engagement, job satisfaction, and employee retention. They were also positively, but more modestly, related to employee mental health.
\end{abstract}

It is more challenging than ever to manage effectively-to recruit top talent, to engage and retain this talent, and to maximize productivity - in the face of fierce competition, more complicated jobs, and changing workforce demographics. Growing numbers of employers are managing quite differently than they did only two decades ago as they attempt to create workplaces in which employees can work more effectively. These efforts have led researchers and management consultants to explore workplace factors that are essential to effective workplaces.

Correspondence should be sent to Jenet I. Jacob, 2061 Joseph F. Smith Building, Brigham Young University, Provo, UT 84602. E-mail: jenet_jacob@byu.edu 
Five of the factors that are frequently identified by management consultants and researchers as essential to an effective workplace focus exclusively on work (Bond, Thompson, Galinsky, \& Prottas, 2003; Crabtree, 2004; Galinsky, Bond, \& Friedman, 1993; Gallup Organization, 2001, 2006; Jones, 2006). These include job autonomy, learning opportunities, supervisor support for job success, coworker team support for job success, and involvement in management decision making. A sixth factor, workplace flexibility, recognizes the relationship between employees' work life and their life outside of work. As noted throughout this special issue, flexible work arrangements have received increasing attention because of changes in the demographics of the workforce and the disruptive effects of increasing work demands on life off the job (Galinsky, Bond, \& Hill, 2004; Jacobs \& Gerson, 2004; Mischel, Bernstein, \& Schmitt, 1999).

Each of these six factors has been associated with positive employer and employee outcomes in previous studies (Bond et al., 2003; Crabtree, 2004; Gallup Organization, 2001, 2006, Galinsky et al., 1993; Glass \& Finley, 2002; Jones, 2006), but they have not been explored together as critical ingredients of effective workplaces. The purpose of this study is twofold: first, to examine the relationship between the six factors that have been associated with workplace effectiveness and the three work outcomes of job engagement, job satisfaction, and employee retention, and the employee outcome of mental health; and second, to examine the relationship between a composite measure of overall workplace effectiveness and the four outcomes. The relationships between workplace factors and organizational and employee outcomes have received increased attention in research on the workplace because of their relationships with important financial outcomes for businesses (Galinsky et al., 2004).

The study uses data from the largest and most comprehensive study of the U.S. workforce, the 2002 National Study of the Changing Workforce $(N=3,504)$. For these analyses a subset of 2,810 waged and salaried employees in the United States was selected. The analyses are descriptive in nature and cannot identify causal relationships between factors of workplace effectiveness and their associated outcomes. Descriptive analyses, however, are an essential first step in examining more complex relationships between job factors and work and employee outcomes.

The study is interested in exploring workplace factors and flexibility options as strategic policies and practices intended to serve business and employee needs, rather than exploring workplace factors designed simply to accommodate the needs of employees. Efforts to create more effective workplaces recognize that people are the employer's greatest resource and that people make the critical difference between loss and profit, between mediocre and stellar business success. The effective workplace is not a "perk" for employees. It is a strategic business tool that may enhance employees' engagement and productivity, thereby serving employers as well as employees. 


\section{RELATED RESEARCH}

The following section reviews research on the relationship between each of the six factors of workplace effectiveness and the four outcomes of job engagement, job satisfaction, employee retention, and employee mental health. The six factors of workplace effectiveness that are reviewed include job autonomy, learning opportunities, supervisor support for job success, coworker team support for job success, involvement in management decision making, and workplace flexibility. The review provides a framework for exploring the relationship between each of the six factors of workplace effectiveness and each of the four outcomes, and the relationship between a composite measure of workplace effectiveness and each of the four outcomes.

\section{Job Autonomy and Work and Employee Outcomes}

Job autonomy has been identified as "the degree to which the job provides substantial freedom, independence, and discretion to the individual" in work content, the method for accomplishing work, and the pace at which work is accomplished (Hackman \& Oldham, 1980, p. 79). Job autonomy emerged as an important dimension of job outcomes following deCharms's (1968) theory of personal causation, which asserted that individuals will "cherish" behavior and results that they perceive as "stemming from [their] own choice" (deCharms, 1968, p. 273). In support of the definition advanced by deCharms, the Gallup Organization found job autonomy to be associated with job engagement and job retention (Gallup, 2001). A later poll found autonomy in how tasks are accomplished and sense of fulfillment in job tasks to be the most frequently cited reasons for liking a job (Jones, 2006).

Perceived job autonomy has also been associated with psychological wellbeing. A study of 418 Norwegian employees found high decision authority to be associated with enhanced psychological functioning and health (Mikkelsen, Saksvik, Eriksen, \& Ursin, 1999). Perceived psychological strain was also moderated by job autonomy when individuals felt more accountability for work outcomes (Hall et al., 2006). These findings suggest that job autonomy may be a potentially important factor of workplace effectiveness.

\section{Learning Opportunities and Work and Employee Outcomes}

Learning opportunities have generally referred to three dimensions of learning on the job: opportunities to learn new things on the job, having a job that requires one to be creative, and being able to influence what happens on the job (Galinsky et al., 2004; Quinn \& Staines, 1979). The Gallup Organization 
found learning opportunities on the job, as with job autonomy, to be associated with increased employee engagement as well as increased employee retention, productivity, and profitability (Harter, Schmidt, \& Keyes, 2000). The availability of learning opportunities was identified as an important predictor of employee satisfaction in a study of numerous U.S. commercial banks (Rowden \& Conine, 2005). Another study found challenging and extensive learning opportunities to be associated with better psychological functioning, subjective health, and coping styles (Mikkelsen et al., 1999). Rowden (2002) concluded that the dramatic difference in higher rates of job satisfaction for employees in small companies relative to large companies could be attributed to the extent of workplace learning opportunities available in small companies.

According to the Active Learning Hypothesis (Karasek \& Thoerell, 1990), most learning takes place in demanding and challenging situations, particularly when an individual feels autonomy in job decision making. Thus, learning opportunities have been associated with job autonomy as mutually reinforcing aspects of work (Mikkelsen et al., 1999). These findings suggest that learning opportunities may also be a potentially important factor of workplace effectiveness.

\section{Supervisor Support and Work and Employee Outcomes}

Supervisor support has been defined as the relationship between subordinate and supervisor which is viewed by the subordinate as having a positive contribution to career development (Kram, 1985). Supervisor support has been characterized as including some or all of the following components: provision of information on how to perform well in a job, realistic expectations of job performance, recognition of good job performance, and support with work problems (Galinsky et al., 2004; Jiang \& Klein, 2000). The Gallup Organization found these characteristics of supervisor support to be associated with increased job engagement as well as less frustration on the job and higher life satisfaction (Gallup, 2006). Supervisor support has also been associated with increased career satisfaction and decreased turnover (Greenhaus, Parasuraman, \& Wormley, 1990). These findings suggested that a key mechanism through which supervisor support facilitated increased job satisfaction and retention was career advancement support (Greenhaus et al., 1990).

\section{Coworker Team Support and Work and Employee Outcomes}

Coworker team support is defined by the feeling that one is really a part of the group and that coworkers provide the support needed to do a good job (Galinsky, Bond, \& Hill, 2004). Both instrumental and affective coworker support in the 
form of facilitating opportunities for success and providing emotional support have been identified as significant contributors to job satisfaction (Ducharme \& Martin, 2000). The Gallup Foundation found that employees who agreed that their organization encouraged close friendship at work were significantly more likely to be extremely satisfied with their place of employment than employees whose organizations did not encourage close friendships (Crabtree, 2004). Studies have also found coworker support to be associated with less psychological strain for employees (Beehr, 1995; Beehr, Jex, Stacy, \& Murray, 2000). For instance, Beehr et al.'s (2000) study of psychological strain for door-to-door salesmen suggested that coworker support may be "calming" for employees by facilitating global feelings of support and communication about stressors. Such findings provide support for including coworker support as a potentially important aspect of an effective workplace with implications for employee mental health and work outcomes including job engagement, satisfaction, and retention.

\section{Involvement in Management Decision Making and Work and Employee Outcomes}

Involvement in management decision making has been defined as having managers at a workplace who actively seek out information and new ideas from employees at all levels of the organization to guide their decision making (Galinsky et al., 2004). Work empowerment theory (Kanter, 1977) has been useful in providing a framework for investigating how structural factors that enable subordinate participation in managerial decision making facilitate psychological empowerment (Laschinger, Purdy, \& Almost, 2007). Psychological empowerment has in turn predicted lower levels of emotional exhaustion and higher job satisfaction (Laschinger, Purdy, Cho, \& Almost, 2006; Laschinger et al., 2007). The Gallup Organization found involvement in management decision making to be associated with job engagement, satisfaction, and retention (Gallup, 2001).

\section{Workplace Flexibility and Work and Employee Outcomes}

Flexibility in when and where work is done has consistently predicted better work relations and job commitment, whereas low levels of flexibility have predicted higher employee turnover (Meyer, 1997). A meta-analysis of flextime studies found workplace flexibility to be associated with decreased absenteeism and increased productivity (Baltes, Briggs, Huff, Wright, \& Neuman, 1999). Flexibility to reduce the number of work hours or to move from full-time to part-time work status was specifically associated with increased organizational commitment and less absenteeism (Blank, 1990; Epstein, Seron, Oglensky, \& Saute, 1999). 
Workplace flexibility including family-supportive policies and management has also been associated with increased job satisfaction (Thomas \& Ganster, 1995). Other flexibility options including alternative work schedules, flextime, and compressed workweeks have also predicted greater job satisfaction and affective commitment to employment (Grover \& Crooker, 1995). The relationship between workplace flexibility, job engagement, and satisfaction supported other findings that indicated that flexibility was also linked to retention (Bond et al., 2003).

Glass and Finley's (2002) review of research on workplace flexibility concluded that there were many robust findings indicating positive outcomes associated with job flexibility on employee outcomes including mental and physical health. As an example, Thomas and Ganster's (1995) study of employees in the health care setting found that scheduling practices that afforded high levels of flexibility showed a significant direct effect on reduced somatic health complaints and enhanced mental and physical health outcomes. These findings provide support for inclusion of workplace flexibility as a factor of workplace effectiveness and predictor of positive outcomes for employers and employees.

\section{HYPOTHESES}

Based on these reviewed findings, two hypotheses were proposed and tested in this study.

H1: Each of the six factors of workplace effectiveness (job autonomy, learning opportunities, supervisor support for job success, coworker team support for job success, involvement in management decision making, and workplace flexibility) will be related positively to three work outcomes (job engagement, job satisfaction, employee retention) and to the employee outcome of mental health.

H2: Overall workplace effectiveness will be related positively to three work outcomes (job engagement, job satisfaction, employee retention) and to the employee outcome of mental health.

Testing these hypotheses is a first step in facilitating increased understanding of the complex relationships between job factors and job and employee outcomes. The analyses specifically enable an exploration of whether employees in workplaces where responsibility is shared between managers and workers, where workers are supported in developing and exercising their skills, and where workers have greater flexibility to manage their work, personal, and family lives will be more committed and engaged in their jobs, experience greater job satisfaction, be more likely to remain with their current employers, and exhibit better mental health. 


\section{METHOD}

\section{Participants}

This study uses data from the 2002 National Study of the Changing Workforce (NSCW), conducted every 5 years by the Families and Work Institute (Bond et al., 2003) to evaluate the relationship between six factors of workplace effectiveness and four outcomes of interest to employers. The NSCW contains hundreds of questions about work, personal, and family life as well as soliciting extensive background and demographic information from respondents. It is frequently cited in the press and in scholarly publications.

The original study's sample consisted of 3,504 respondents from a nationwide cross section of employed adults interviewed by telephone between October 2002 and June 2003. Calls were made to a stratified (by region) unclustered random probability sample generated by random-digit-dial methods. Interviews averaged 45 minutes in length and were conducted using a computer-assisted telephone interviewing (CATI) system.

The response rate was 52\% of eligible households. Response rate is defined as the number of complete interviews divided by the number of eligible reporting units in the sample. This response rate follows guidelines of the Council of American Survey Research Organizations (CASRO) and the American Association for Public Opinion Research (AAPOR).

\section{Study Sample}

The sample used in the current analysis included the 2,810 adults from the population of the original study $(N=3,504)$ who were waged and salaried employees. Business owners and self-employed respondents were not included in the sample used in the current analysis. The sample was first weighted by the number of eligibles in the respondents' households and then to proportions in the March 2002 Current Population Survey for eligibles per household (number of employed persons 18 and older per household with any employed person 18 or older), eligible men and women, and eligibles with different educational levels. The average design effect for the weighted sample is estimated to be 1.25. When this design effect is applied, the maximum sampling error for waged and salaried sample statistics $(n=2,810)$ is approximately $\pm 2 \%$.

\section{Measures}

\section{Measures of Factors of Workplace Effectiveness}

The six factors of workplace effectiveness that were measured included job autonomy, learning opportunities, supervisor support for job success, coworker 
team support for job success, involvement in management decision making, and workplace flexibility. A composite measure of overall workplace effectiveness was created to address the study's second hypothesis.

Job autonomy. An index of job autonomy $(\alpha=.71)$ was produced by calculating the mean score of responses to three questions drawn from the 1977 Quality of Employment Survey (QES; Quinn \& Staines, 1979). The questions included "In my employment, (a) I have freedom to decide what I do on my job, (b) I have basic responsibility for deciding how my job gets done, and (c) I have a lot of say about what happens on my job." Responses ranged from 1 (strongly disagree) to 4 (strongly agree). The top quartile of job autonomy scores were classified as "high," the middle two quartiles were classified as "mid," and the bottom quartile were classified as "low."

Learning opportunities on the job. An index of learning opportunities on the job $(\alpha=.64)$ was produced by calculating the mean score of responses to three questions drawn from the 1977 QES (Quinn \& Staines, 1979). The questions included "In my employment, (a) I am required to learn new things on the job, (b) I have a job that requires one to be creative, and (c) I have a job that allows me to develop my skills and abilities." Responses ranged from 1 (strongly disagree) to 4 (strongly agree). The top quartile of learning opportunities on the job scores were classified as "high," the middle two quartiles were classified as "mid," and the bottom quartile were classified as "low."

Supervisor support for job success. An index of supervisor support for job success $(\alpha=.89)$ was produced by calculating the mean score from responses to four questions drawn from previous work by the Families and Work Institute (Galinsky et al., 1993). The questions included "My supervisor or manager (a) keeps me informed of things I need to know to do my job well, (b) has expectations of my performance on the job that are realistic, (c) recognizes when I do a good job, and (d) is supportive when I have a work problem." Responses ranged from 1 (strongly disagree) to 4 (strongly agree). The top quartile of supervisor support for job success scores were classified as "high," the middle two quartiles were classified as "mid," and the bottom quartile were classified as "low."

Coworker team support for job success. An index of coworker team support for job success $(\alpha=.73)$ was produced by calculating the mean score from responses to three questions drawn from previous Families and Work Institute research projects. The questions included the following: (a) "I feel I am 
part of the group I work with" (Galinsky et al., 1993), (b) "I have the support from my coworkers that I need to do a good job" (Galinsky et al., 2004), and (c) "I have the support from my coworkers that I need to manage work/family life" (Galinsky et al., 2004). Responses ranged from 1 (strongly disagree) to 4 (strongly agree). The top quartile of coworker team support for job success scores were classified as "high," the middle two quartiles were classified as "mid," and the bottom quartile was classified as "low."

Involvement in management decision making. The involvement in management decision-making indicator was created using the following question: "I have managers at my workplace who actively seek out information and new ideas from employees at all levels of the organization to guide their decision making" (Galinsky et al., 2004). Responses ranged from 1 (strongly disagree) to 4 (strongly agree). Those responding " 1 " were classified as "low," those responding " 2 " or " 3 " were classified as "mid," and those responding "4" were classified as "high."

Flexible workplace. An index of flexible workplace was created by adding together the total number of indicators of flexibility that were responded to with a "yes" by the respondent. Each response was coded as 1 (yes) or 0 (no). Several of the questions used to create the indicators were drawn from the 1977 QES (Quinn \& Staines, 1979) and the remainder were developed and used by the Families and Work Institute during the past 15 years. The questions included the following: "In my workplace, I (a) have traditional flextime (set daily hours within a range periodically), (b) have daily flextime, (c) am allowed to take time off during the workday to address family matters, (d) am able to take a few days off to care for a sick child without losing pay, having to use vacation days, or having to make up an excuse for absence, (e) am able to work some regular hours at home, (f) am able to take breaks when I want to, (g) have a work shift that is desirable, (h) have complete or a lot of control over my work schedule, (i) am able to work part-time (if currently full-time) or full-time (if currently part-time) in my current position, (j) am able to work a compressed workweek, (k) am able to work part-year in my current position, (1) believe that one can use flexible work arrangements without jeopardizing job advancement, and $(\mathrm{m})$ am seldom required to work paid or unpaid overtime with little or no notice." The top quartile of flexible workplace scores were classified as "high," the middle two quartiles were classified as "mid," and the bottom quartile of scores were classified as "low."

Overall workplace effectiveness. The composite measure of overall workplace effectiveness was created by averaging the scores from the six factors 
of workplace effectiveness: job autonomy, learning opportunities on the job, supervisor support for job success, coworker team support for job success, involvement in management decision making, and flexible workplace options. The top quartile of the composite workplace effectiveness scores were classified as "effective," the middle two quartiles were classified as "neither effective nor ineffective," and the bottom quartile was classified as "ineffective."

\section{Measures of Work and Employee Outcomes}

The four work and employee outcomes that were measured in order to evaluate their relationship with the six factors of workplace effectiveness included job engagement, job satisfaction, employee retention, and employee mental health.

Job engagement. Job engagement was measured by a single direct question that has been used in previous Families and Work Institute projects (Galinsky et al., 1993): "Please ... tell me whether you strongly agree, somewhat agree, somewhat disagree, or strongly disagree [with the following statement]: I am willing to work harder than I have to, to help my company succeed." The $61 \%$ of respondents who agreed strongly with this statement were categorized as "highly engaged." The $31 \%$ of respondents who agreed somewhat with this statement were categorized as "somewhat engaged." The $8 \%$ of respondents who disagreed somewhat or strongly disagreed were categorized as "disengaged" from their jobs.

Job satisfaction. An index of job satisfaction $(\alpha=.68)$ was produced by combining the standardized mean scores from responses to two questions that have been widely used in workplace research and were used in the 1977 QES (Quinn \& Staines, 1979).The first question asked, "All in all, how satisfied are you with your job?" Responses ranged from 1 (not satisfied at all) to 4 (very satisfied). The second question asked, "Knowing what you now know, if you had to decide all over again whether to take the job you now have, what would you decide?" Responses were coded as 1 (definitely NOT take job), 2 (have some second thoughts), and 3 (take the same job again without hesitation). The top quartile of job satisfaction standardized scores were classified as "high," the middle two quartiles were classified as "mid," and the bottom quartile were classified as "low."

Job retention. Job retention was based on a single question that has been used extensively in survey research with employees and was used in the 1977 QES (Quinn \& Staines, 1979): “Taking everything into consideration, how likely 
is it that you will make a genuine effort to find a new job with another employer within the next year?" Responses included very likely, somewhat likely, or not at all likely. The $61 \%$ of respondents who said they were not at all likely to make a genuine effort to find a new job were categorized as "high job retention." The $21 \%$ of respondents who said they were "somewhat likely" were categorized as "somewhat job retention." The $17 \%$ of respondents who said they were very likely to make a genuine effort to find a new job were categorized as "low job retention."

Employee mental health. An index of employee mental health $(\alpha=.78)$ was produced by calculating the mean score from responses to seven questions drawn from psychiatric/medical research that tap various dimensions of stress, coping, and depression (Cohen, Kamarck, \& Mermelstein, 1983; Whooley, Avins, Miranda, \& Browner, 1997). These questions included (a) "How often in the past month have you been bothered by minor health problems such as headaches, insomnia, or stomach upsets?" (b) "How often in the past month have you had trouble sleeping to the point that it affected your performance on and off the job?" (c) "How often in the past month have you felt nervous and stressed?" (d) "How often in the past month have you felt unable to control the important things in your life?" (e) "How often in the past month have you felt that difficulties were piling up so high you could not overcome them?" (f) "During the past month, have you been bothered by feeling down, depressed, or hopeless?" and (g) "During the past month, have you been bothered by little interest or pleasure in doing things?" Employees with scores in the top 25\% of means calculated from responses to these questions were classified as "high." Employees with scores in the bottom 25\% were classified as "low." Employees with scores in the middle two quartiles were classified as "mid."

\section{Analyses}

Two sets of analytical tasks were performed to address the hypotheses advanced by this study. The first task involved transforming the variables into categorical variables. The second task involved cross-tabulation analyses. The statistical analyses used were not inferential. This is due to the fact that the paper is based on a report from the Work and Families Institute directed specifically to an audience of workplace managers. The current study does not deviate from the analyses used in the original report, but the strength of the relationships produced from the analyses indicates statistical significance. The two sets of analytical tasks that were performed determined the relationship of each hypothesized factor of workplace effectiveness to each outcome, and the relationship between the composite measure of overall workplace effectiveness and each of the four outcomes. 


\section{Transforming Variables Into Categorical Variables}

The six factors of workplace effectiveness, the composite of overall workplace effectiveness, and the four outcome factors were trichotomized into high, mid, and low values. "High" was defined as the top quartile of the distribution of values for each variable, whereas "low" was defined as the bottom quartile, leaving "mid" as the middle two quartiles. Given the highly skewed distribution of responses for some variables and the limited number of possible values for responses, the proportion of responses in the low $/ \mathrm{mid} / \mathrm{high}$ categories sometimes varies substantially from the desired $25 \% / 50 \% / 25 \%$ distribution.

\section{Cross-Tabulation Analyses}

Cross-tabulation analyses were performed by comparing respondents in the top and bottom quartiles of the distribution for each of the six factors of workplace effectiveness and the composite of overall workplace effectiveness with respondents in the "high" and "low" categories of each of the four outcomes. To evaluate the relationship between workplace effectiveness and job engagement, the top and bottom quartiles for each of the six factors of workplace effectiveness and overall effectiveness were cross-tabulated with respondents who were "highly engaged" and "disengaged." For job satisfaction, the top and bottom quartiles for each of the six factors of workplace effectiveness and overall effectiveness were cross-tabulated with respondents who were classified as "high job satisfaction" and "low job satisfaction." For job retention, the top and bottom quartiles for each of the six factors of workplace effectiveness and overall effectiveness were cross-tabulated with respondents who were categorized as "high job retention" and "low job retention." For mental health, the top and bottom quartiles for each of the six factors of workplace effectiveness and overall effectiveness were cross-tabulated with respondents who were categorized as "high mental health" and "low mental health."

\section{RESULTS}

The results for the cross-tabulation analyses used to address hypothesis 1, which explored the relationship between each of the six job factors and the four outcomes, are presented in Table 1. The results for the cross-tabulation analyses used to address hypothesis 2 , which explored the relationship between a composite measure of overall workplace effectiveness and the four outcomes, are presented in Table 2. 
TABLE 1

Relationships Between Job Factors and Workplace Flexibility and High Job Engagement, High Job Satisfaction, High Job Retention, and High Mental Health for Each Factor of Workplace Effectiveness

\begin{tabular}{|c|c|c|c|c|}
\hline $\begin{array}{l}\text { Factor of Workplace } \\
\text { Effectiveness } \\
(n=2810)\end{array}$ & $\begin{array}{l}\% \text { High Job } \\
\text { Engagement }\end{array}$ & $\begin{array}{l}\text { \% High Job } \\
\text { Satisfaction }\end{array}$ & $\begin{array}{c}\% \text { High Job } \\
\text { Retention }\end{array}$ & $\begin{array}{l}\% \text { High } \\
\text { Mental } \\
\text { Health }\end{array}$ \\
\hline \multicolumn{5}{|c|}{ Degree of job autonomy } \\
\hline High & 73 & 65 & 73 & 36 \\
\hline Low & 53 & 27 & 49 & 20 \\
\hline \multicolumn{5}{|c|}{ Extent of learning opportunities } \\
\hline High & 80 & 72 & 74 & 34 \\
\hline Low & 49 & 29 & 50 & 22 \\
\hline \multicolumn{5}{|c|}{ Extent of supervisor support } \\
\hline High & 79 & 64 & 68 & 31 \\
\hline Low & 46 & 24 & 47 & 21 \\
\hline \multicolumn{5}{|c|}{ Extent of coworker support } \\
\hline High & 76 & 66 & 71 & 34 \\
\hline Low & 42 & 18 & 47 & 15 \\
\hline \multicolumn{5}{|c|}{$\begin{array}{l}\text { Extent of involvement in managerial } \\
\text { decisions }\end{array}$} \\
\hline High & 74 & 62 & 71 & 31 \\
\hline Low & 38 & 16 & 43 & 16 \\
\hline \multicolumn{5}{|c|}{ Extent of workplace flexibility } \\
\hline High & 66 & 67 & 72 & 35 \\
\hline Low & 56 & 23 & 49 & 19 \\
\hline
\end{tabular}

\section{Analysis of Each Workplace Effectiveness Factor and Outcomes}

Job autonomy. The positive implications of job autonomy, learning opportunities, decision-making involvement, coworker/supervisor support, and flexible work arrangements for job engagement are evident in Table 1. Employees in workplaces categorized as "high" in any of the six factors of workplace effectiveness were more likely to have high job engagement scores. For example, $73 \%$ of employees in workplaces with a high degree of job autonomy had high job engagement scores compared with 53\% of those with a low degree of job autonomy. Similarly, $80 \%$ of employees in workplaces rated "high" in the extent of learning opportunities had high job engagement scores compared with $49 \%$ of those with fewer learning opportunities. Employees from workplaces with greater decision-making involvement, coworker/supervisor support, or flexible work arrangements were also more likely to be more engaged with their jobs. 
TABLE 2

Relationship Between Job and Employee Outcomes and the Composite Measure of Overall Workplace Effectiveness

\begin{tabular}{lc}
\hline Outcome Level $(n=2810)$ & $\begin{array}{c}\text { \% Overall } \\
\text { Workplace } \\
\text { Effectiveness }\end{array}$ \\
\hline Degree of job engagement & \\
High & 82 \\
Mid & 15 \\
Low & 3 \\
Degree of job satisfaction & \\
High & 81 \\
Mid & 17 \\
Low & 2 \\
Degree of job retention & \\
High & 77 \\
Mid & 14 \\
Low & 9 \\
Level of mental health & \\
High & 38 \\
Mid & 49 \\
Low & 15 \\
\hline
\end{tabular}

Job satisfaction. The positive implications of job autonomy, learning opportunities, decision-making involvement, coworker/supervisor support, and workplace flexibility for job satisfaction are also revealed in Table 1. Employees in workplaces categorized as "high" in any of the six factors of workplace effectiveness were more likely to have high job satisfaction scores. For example, $72 \%$ of employees in workplaces categorized as "high" in the extent of learning opportunities had high job satisfaction scores compared with $29 \%$ of those categorized as "low" in the extent of learning opportunities. Similarly, 66\% of employees in workplaces with greater coworker support had high job satisfaction scores compared with $18 \%$ of those with less coworker support. Employees from workplaces with greater job autonomy, supervisor support, involvement in decision making, and workplace flexibility were also more likely to have high job satisfaction.

Job retention. Table 1 further provides evidence of the positive implications of job autonomy, learning opportunities, decision-making involvement, coworker/supervisor support, and workplace flexibility for job retention. Employees in workplaces categorized as "high" in any of the six factors of workplace effectiveness were more likely to have high job retention, as with job 
engagement and job satisfaction. For example, $73 \%$ of employees in workplaces with a high degree of job autonomy also rated high in job retention compared to $49 \%$ of employees with a low degree of job autonomy. Employees from workplaces with greater learning opportunities, supervisor support, coworker support, involvement in decision making, and workplace flexibility were also more likely to rate high in job retention.

Mental health. Table 1 also presents the percentage of employees from workplaces rated high and low in each factor of workplace effectiveness who exhibited very good mental health. The findings demonstrate positive outcomes associated with each of the factors of workplace effectiveness on mental health, although they were not as dramatic as for the other outcomes. For example, $34 \%$ of employees with a high degree of coworker support exhibited very good mental health compared to $15 \%$ of those with a low degree of coworker support.

\section{Analysis of Composite Measure of Overall Workplace Effectiveness and Outcomes}

Table 2 presents the relationships between the composite measure of overall workplace effectiveness and each of the four job outcomes. The percentage of respondents with high, mid, and low level scores for each of the four job outcomes and the corresponding percentages of respondents with high, mid, and low level scores for overall workplace effectiveness are illustrated. Among employees in highly effective workplaces, $82 \%$ expressed high levels of job engagement, $81 \%$ expressed high levels of job satisfaction, and $77 \%$ expressed high job retention. Very few employees in effective workplaces were rated "low" on any of the desirable outcomes considered, while most were rated "high." The only exception to this pattern is mental health where nearly a majority of employees in effective workplaces are rated in the middle category. Findings from Table 2, however, indicated that more than $2 \frac{1}{2}$ times as many employees in effective workplaces (38\%) as in ineffective workplaces (15\%) exhibited very good mental health.

\section{DISCUSSION}

This study explored the relationships between six factors of workplace effectiveness and four outcomes of importance to employers (job engagement, job satisfaction, employee retention, and employee mental health). The study also explored the relationship between a composite measure of overall workplace 
effectiveness and the four outcomes. The findings indicated that each of six factors of workplace effectiveness was positively related to job engagement, job satisfaction, and employee retention. They were also each positively, but more modestly, related to employee mental health. The composite measure of overall workplace effectiveness was more associated with each of the outcomes than the individual factors of workplace effectiveness.

\section{Combined Workplace Effectiveness and Outcomes}

Results from the descriptive analyses confirm previous studies that have identified these factors as associated with positive outcomes. They also indicate a positive relationship between the combined effect of all six factors of workplace effectiveness and outcomes that benefit both employers and employees. A more effective and flexible workplace was associated with increased job engagement, job satisfaction, employee retention, and employee mental health. Respondents with scores in the highest quartiles of each of the six factors of workplace effectiveness were more likely to have higher job engagement, higher job satisfaction, higher job retention, and higher mental health scores than respondents with scores in the lowest quartiles of the six factors. Further, a higher mean score for the six combined workplace factors was more strongly associated with higher scores for each outcome than each of the factors independently.

\section{Combined Workplace Effectiveness and Mental Health}

The relationship between workplace effectiveness and mental health is important to note given that employees with poorer mental health have lower productivity on the job and generate higher health care costs for employers-not to mention the pain, suffering, and costs experienced by the workers themselves and their families (Burton, Conti, Chen, Schultz, \& Edington, 1999). Obviously, factors off the job as well as factors on the job may affect the mental health of employees. However, the difference in the proportions of employees judged to have good mental health in effective and ineffective workplaces suggests that workplace factors may play an important role.

Further exploration of the finding that employees in effective workplaces rated in the middle category rather than the highest category for mental health may be explained by one aspect of our measure of mental health. Stress, measured by the frequency of feeling stressed and not having enough sleep, is the main reason why more employees in effective workplaces are not rated as having "very good" mental health. Stress and inadequate sleep are pervasive within today's workforce as employees struggle to manage unprecedented work demands and personal and family responsibilities. Uncertain job security during the period of data collection (late 2002 to early 2003) may also have been a stressor. 
More than $2^{1 / 2}$ times as many employees in effective workplaces (38\%) as in ineffective workplaces (15\%), however, exhibited very good mental health. This suggests that employees may be able to handle relatively high levels of stress in their lives if they have sufficient supports on and off the job. More effective workplaces may actually protect employees from stress.

\section{Workplace Effectiveness and Employers}

In addition, the findings suggest that unlike traditional fringe benefits, a more effective workplace-including more flexible work arrangements-for employees can typically be provided without any direct costs to the employer. To the extent that effective workplace options do not impose costs but do generate benefits to the bottom line, a positive return on investment is ensured. These are notable findings-supported by various small-scale, nonrepresentative studies and confirmed by this large nationally representative survey of employees. When workers are empowered and supported, they are more likely to be satisfied with their jobs, more committed and engaged, and more likely to stay with their current employers. They may also be more likely to exhibit better mental health, which bodes well for higher productivity and lower health care costs.

\section{Workplace Effectiveness and Workplace Flexibility}

The findings about workplace flexibility are particularly noteworthy because the relationships between workplace flexibility and business outcomes have not received the same attention as the relationships of other aspects of effective workplaces to the outcomes employers care about. This analysis found that flexible work arrangements had the same positive relationships with measures of business success outcomes for employees of different ages and occupational groups. Similar results have been reported elsewhere for men and women, single and married employees, as well as parents and nonparents and employees with and without elder care responsibilities (Galinsky et al., 2004). This suggests that flexible workplaces do not merely benefit small segments of the workforce - women, mothers, or caregivers-but the workforce as a whole.

\section{LIMITATIONS}

There are several limitations in the current analysis to consider in interpreting the results and their implications. First, the analyses were only descriptive and exploratory. They do not establish any causal relationships between the six factors of workplace effectiveness and job engagement, job satisfaction, employee retention, and employee mental health. Cross-tabulation analyses suggest a 
relationship but do not identify the direction or causality of the relationship. Second, exploratory cross-tabulation analyses provide little information about the extent to which each factor influences each of the four outcomes. Future research would further understanding by isolating the unique effects of each factor and their effect sizes.

Third, the nature of survey research and use of phone interview surveys limits the extent to which constructs including job engagement, job satisfaction, job retention, and mental health can be evaluated. Previous use of all of these measures further establishes the reliability and validity of the measures, but the use of large representative samples generally limits the capacity to ask the number of questions that would increase reliability and validity. For example, if there had been more items in the measure of job engagement, it is likely that there would have been fewer employees who were identified as "highly engaged" than were found by asking only one question.

Finally, differences in measures across studies of the workplace may make it difficult to compare findings and identify patterns in the relationships between factors of workplace effectiveness and employer and employee outcomes. The National Study of the Changing Workforce has attempted to establish more uniformity in measures by using the same measures consistently in their own studies and those that were also used in the QES (Quinn \& Staines, 1979). But other studies that have attempted to look at these factors have used a variety of measures, making it difficult to interpret and compare findings. Given these limitations, the findings from this study provide needed and unique insight into the workplace factors that are essential to effective workplaces and suggest important implications for employers as well as employees.

\section{IMPLICATIONS FOR MANAGERS}

For some time, management theory, with limited support from small-scale and often nonrepresentative empirical research studies, has argued that sharing greater responsibility with employees and increasing workplace flexibility have positive effects on the bottom line. These findings from the 2002 National Study of the Changing Workforce provide support from a nationally representative survey of workers that this course of action makes sense. Moreover, as growing numbers of employees experience greater autonomy in their jobs and greater flexibility in their workplaces, we expect it to become increasingly difficult for employers who are not on board to attract, grow, and retain the talent they need.

In particular, we suggest that employers consider new options for flexibility—not as "perks" designed to accommodate employee needs, but as strategic management tools that can improve business performance while also helping employees manage the sometimes conflicting demands of their work, 
personal, and family lives. When employees are unable to manage their "whole" lives effectively because of inflexible work arrangements, work suffers and turnover often results.

The effective and flexible workplace requires new ways of managing and working. It requires both managers and employees to assume greater responsibilities in organizing and scheduling work. Some managers may find it difficult to break with traditional ways of doing things, and some employees may not be able to handle new responsibilities of working more flexibly. In addition, some jobs are less conducive to flexibility than others. However, organizations that have committed themselves to developing more effective and flexible workplaces are typically strongly persuaded that they have made the right decision and have reaped benefits far outweighing costs.

\section{CONCLUSION}

Findings from these descriptive analyses suggest that the workplace factors of job autonomy, learning opportunities, supervisor support for job success, coworker team support for job success, and involvement in management decision making combined with workplace flexibility are associated with important employer and employee outcomes. Although each of these factors is positively related to job engagement, job satisfaction, employee retention, and employee mental health, the combination of all of these factors of workplace effectiveness shows an even stronger positive relationship with these outcomes. Although the analyses cannot establish a causal relationship, they suggest that managers and their employees benefit both on and off the job when the workplace provides an effective work environment. When implemented in the workplace, these factors of workplace effectiveness become strategic management tools that can improve employee performance and enable a more facilitative relationship between employees' work and family lives.

\section{REFERENCES}

Baltes, B. B., Briggs, T. E., Huff, J. W., Wright, J. A., \& Neuman, G. A. (1999). Flexible and compressed workweek schedules: A meta-analysis of their effects on work-related criteria. Journal of Applied Psychology, 84, 496-513.

Beehr, T. A. (1995). Psychological stress in the workplace. London: Routledge.

Beehr, T. A., Jex, S. M., Stacy, B. A., \& Murray, M. A. (2000). Work stressors and coworker support as predictors of individual strain and job performance. Journal of Organizational Behavior, 21, 391-405.

Blank, R. M. (1990). Are part-time jobs bad jobs? In G. Burtless (Ed.), A future of lousy jobs?: The changing structure of U.S. wages (pp. 123-155). Washington, DC: The Brookings Institute. 
Bond, J. T., Thompson, C., Galinsky, E., \& Prottas, D. (2003). Highlights of the 2002 National Study of the Changing Workforce. New York: Families and Work Institute.

Burton, W. N., Conti, D. J., Chen, C., Schultz, A. B., \& Edington, D. W. (1999). The role of health risk factors and disease on worker productivity. Journal of Occupational and Environment Medicine, 41(10), 863-877.

Cohen, S., Kamarck, T., \& Mermelstein, R. (1983). A global measure of perceived stress. Journal of Health and Social Behavior, 24, 385-396.

Crabtree, S. (2004). Getting personal in the workplace: Are negative relationships squelching productivity in your company? The Gallup Management Journal. Retrieved July 17, 2007, from http:/www.govleaders.org/gallup_article_getting_personal.htm

deCharms, R. (1968). Personal causation: The internal affective determinants of behavior. New York: Plenum Press.

Ducharme, L. J., \& Martin, J. K. (2000). Unrewarding work, coworker support, and job satisfaction: A test of the buffering hypothesis. Work and Occupations, 27(2), 223-243.

Epstein, C. F., Seron, C., Oglensky, B., \& Saute, R. (1999). The part-time paradox: Time norms, professional lives, family, and gender. New York: Routledge.

Galinsky, E., Bond, J. T., \& Friedman, D. E. (1993). The changing workforce: Highlights of the 1992 national study. New York: Families and Work Institute.

Galinsky, E., Bond, J. T., \& Hill, E. J. (2004). When work works: A status report on workplace flexibility. Who has it? Who wants it? What difference does it make? New York: Families and Work Institute. Retrieved July 17, 2007, from http://familiesandwork.org/3w/research/downloads/ status.pdf.

Gallup Organization. (2001, March 15). What your disaffected workers cost. Gallup Management Journal. Retrieved July 17, 2007, from http://gmj.gallup.com/content/439/What-Your-DisaffectedWorkers-Cost.aspx

Gallup Organization. (2006, January 12). Feeling good matters in the workplace. Gallup Management Journal. Retrieved July 17, 2007, from http://gmj.gallup.com/content/20770/GallupStudy-Feeling-Good-Matters-in-the.aspx

Glass, J., \& Finley, A. (2002). Coverage and effectiveness of family-responsive workplace policies. Human Resource Management Review, 12(3), 313-337.

Greenhaus, J. H., Parasuraman, S., \& Wormley, W. M. (1990). Race effects of organizational experience, job performance evaluation, and career outcomes. Academy of Management Journal, 33(1), 64-96.

Grover, S. L., \& Crooker, K. J. (1995). Who appreciates family-responsive human resource policies: The impact of family-friendly policies on the organizational attachment of parents and non-parents. Personnel Psychology, 48, 271-288.

Hackman, J. R., \& Oldman, G. R. (1980). Work redesign. Reading, MA: Addison Wesley.

Hall, A. T., Royle, M. T., Brymer, R. A., Perrewe, P. L., Ferris, G. R., \& Hochwarter, W. A. (2006). Relationships between felt accountability as a stressor and strain reactions: The neutralizing role of autonomy across two studies. Journal of Occupational Health Psychology, 11(1), 87-99.

Harter, J. K., Schmidt, F. L., \& Keyes, C. L. (2002). Well-being in the workplace and its relationship to business outcomes: A review of the Gallup Studies. In C. L. Keyes \& J. Haidt (Eds.), Flourishing: The positive person and the good life (pp. 205-224). Washington, DC: American Psychological Association.

Jacobs, J. A., \& Gerson, K. (2004). The time divide: Work, family and gender inequality. Cambridge, MA: Harvard University Press.

Jiang, J. J., \& Klein, G. (2000). Supervisor support and career anchor impact on the career satisfaction of the entry-level information systems professional. Journal of Management Information Systems, 16(3), 219-230. 
Jones, J. M. (2006, August). Personal fulfillment frequently cited as a top job "like.” Report on Gallup Poll. The Gallup Project. Retrieved July 17, 2007, from http://www.galluppoll.com/content/ content/?ci=24010.

Kanter, R. M. (1977) Men and women of the corporation. New York: Basic Books.

Karasek, R. A., \& Thoerell, T. (1990). Health, work stress, productivity, and the reconstruction of working life. New York: Basic Books.

Kram, K. E. (1985). Mentoring at work: Developmental relationships in organizational life. Glenview, IL: Scott, Foresman.

Laschinger, H. K. S., Purdy, N., \& Almost, J. (2007). The impact of leader-member exchange quality, empowerment, and core self-evaluation on nurse manager's job satisfaction. The Journal of Nursing Administration, 37(5), 221-229.

Laschinger, H. K. S., Purdy, N., Cho, J., \& Almost, J. (2006). Antecedents and consequences of first line managers' perceptions of organizational support: Testing Eisenberger's model in nursing settings. Nursing Economics, 23, 1-10.

Meyer, J. A. (1997, February). Examining workplace flexibility across work and family domains. Dissertation Abstracts International: Section B: The Sciences and Engineering, 57(8-B), 5375.

Mikkelsen, A., Saksvik, P., Eriksen, H. R., \& Ursin, H. (1999). The impact of learning opportunities and decision authority on occupational health. Work \& Stress, 13(1), 20-31.

Mischel, L., Bernstein, J., \& Schmitt, J. (1999). The state of working America 1998-1999. Ithaca, NY: Cornell University Press.

Quinn, R. P., \& Staines, G. L. (1979). The 1977 Quality of Employment Survey. Ann Arbor, MI: Institute for Social Research, University of Michigan.

Rowden, R. (2002). The relationship between workplace learning and job satisfaction in small to mid-sized businesses. Human Resource Development Quarterly, 13, 407-426.

Rowden, R. W., \& Conine, C. T., Jr. (2005). The impact of workplace learning on job satisfaction in small U.S. commercial banks. Journal of Workplace Learning, 17(4), 215-230.

Thomas, L. T., \& Ganster, D. C. (1995). Impact of family-supportive work variables on work-family conflict and strain: A control perspective. Journal of Applied Psychology, 80, 6-15.

Whooley, M. A., Avins, A. L., Miranda, J., \& Browner, W. S. (1997). Case finding instruments for depression. Journal of General Internal Medicine, 12, 439-445. 